\title{
The Functionalization of Trialkoxo Hexavanadates, the Treasure at the End of the Great Route
}

\author{
Nan Wang, Bo Huang, Zicheng Xiao*,and Pingfan Wu* \\ Institute of POM-based Materials, Hubei University of Technology, China
}

Received: 漹 February 15, 2018; Published: 制 February 27, 2018

*Corresponding author: Pingfan Wu, Zicheng Xiao, Institute of POM-based Materials, Hubei Provincial Key Laboratory of Green Materials for Light Industry, Hubei University of Technology, Wuhan, China, Email: zichxiao@hotmail.com

\begin{abstract}
Organic fictionalization with trimethylolalkoxy is a beneficial strategy for excavating the excellent potential properties of polyoxovanadates towards advanced inorganic-organic materials.
\end{abstract}

\section{Introduction}

Polyoxometalates are well-known for the unique topological structures and functional activities of the pure inorganicor inorganic-organic clusters. As an important branch of polyoxometalates chemistry, polyoxovanadates (POVs), especially the Lindquist-type POVs have attracted much more interests due to its excellent application in catalysis, magnetism, and biology and photo chemical activity. During the past decades, the functionalization of POVs has attracted increasing attention and their electronic, magnetic properties, potential catalytic capabilities and bioactivities have been widely studied [1-3] .The Lindquisttype alcohol-hexavanadates are the largest subclass of the POV derivatives, in which the hexavanadate core $\left\{\mathrm{V}_{6} \mathrm{O}_{19}\right\}$ is stabilized by trios legends $\left(\mathrm{HOCH}_{2}\right) 3 \mathrm{CR}\left(\mathrm{R}=-\mathrm{CH}_{3},-\mathrm{NO}_{2},-\mathrm{CH}_{2} \mathrm{OH}\right.$, etc. $)$. The pioneer investigation of these derivatives were mainly done by Zubieta [4-6].. And Miller [7].The first and most common examples of trialkoxo-hexavanadates $\left[(\mathrm{n}-\mathrm{Bu})_{4} \mathrm{~N}_{2}\left[\mathrm{~V}_{6} \mathrm{O}_{13}\left\{\left(\mathrm{OCH}_{2}\right)_{3} \mathrm{CR}\right\}_{2}\right]\right.$ reported by Zubieta (Figure 1).

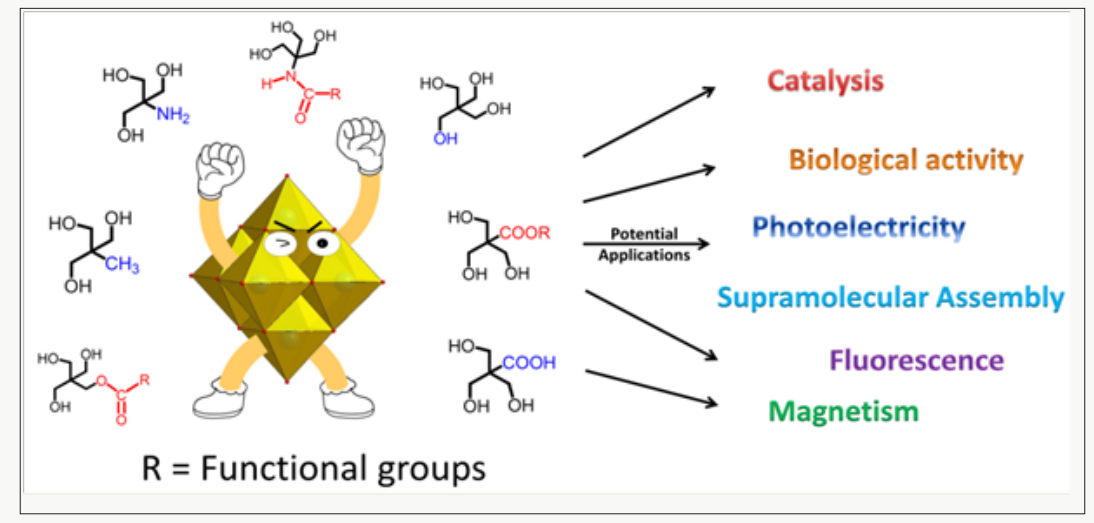

Figure 1:

In 1990 were prepared by solvent reaction of de cavanadate salts and trios legends. In their anion structures, two trialkoxo legends coordinated to three vanadium ions in a triangular arrangement, occupying the two opposite faces of the hexavanadate core. By adding different resultants into the reaction system, mixed-valence or fully reduced hexavanadate derivatives can be obtained [5,7] . Except for di-substituted trialkoxo-hexavanadates, Zubieta also reported the hexavanadates are stabilized by three or four trialkoxo legends prepared through hydrothermal reaction of vanadium oxides, trios legends and different mineralize in reagents [6]. Although the researches of POV derivatives have been last for 
a long period, the progress in the field was still slow compared to the poly oxomolybdates and polyoxotungstates. The controllable synthesis of the POV hybrids is still a challenging task as it always faces difficulties such as unexpected side reactions and low yield of the target products due to the high valence of the vanadium atom. In this case, post-functionalization strategy could be a more promising way as it won't involve the reconstruction of the POV clusters and can reduce side reactions [8].

Trialkoxo-hexavanadates can be the excellent POV platforms for post-functionalization because of their conveniently preparation and high stability. Further modification of trialkoxo-hexavanadate by coordination reactions have been explored by Hill and Hasenknopf [9-12]. In these works, trialkoxo hexavanadates with terminal organic groups that have strong ability to bind metal ions (such as pyridyl or carboxyl groups) were synthesized at first, and then further reacted with metal ions to form coordination complexes. By this means, POV-based coordination networks or supra molecular assemblies with interesting shapes can be obtained. On the other hand, further modifications of trialkoxo hexavanadates through common organic reactions have also been developed recently. Wei and co-workers reported a new approach to functionalize pentaerythritol-derived hexavanadates via etherification reaction catalyzed by 4-(N, N-dimethylamino) pyridine (DMAP) $[13,14]$.

A novel hexavanadate derivative with two C18 alkyl chains was reported and an unexpected blue luminescence from the inorganic clusters is observed in solution. However, due to the poor reactivity of the hydroxyl groups on the pentaerythritol-derived hexavanadates, the choice of the organic legends was limited to a few organic anhydrides. To overcome this drawback, several attempts have been done to introduce more active organic groups on the POV cluster. Hill reported a trialkoxo-hexavanadate with amino groups and synthetic approach was improved by Wei's group $[15,16]$. This new derivative can be easily functionalized by admiration reactions. Wei also reported a trialkoxo-hexavanadates containing carboxyl groups through the oxidation of pentaerythritol-derived hexavanadates, which can be further modified by coordination or etherification reactions $[17,18]$. Our group developed a step-bystep approach for the post-functionalization of POVs, in which the pentaerythritol-derived hexavanadates first reacted with cyclic anhydride, resulting in a new carboxyl-containing POV hybrid, then modified with organic amines in the next step [19].

The post-functionalization of POVs have made great progress in recent years, however, most of the research are based on the fullyoxidized di-substituted trialkoxo-hexavanadates. Recently ourgroup have successfully synthesized tri-substituted and tetra-substituted trialkoxo-hexavanadate containing amino groups by hydrothermal reactions of metavanadate salts, tries (hydroxymethyl)methyl amino methane and hydrazine reluctant $[20,21]$. These compounds can be further functionalized through am ideation reactions and can be used as a novel POV platforms. Furthermore, the vanadium cluster in these examples are mix-valence or fully-reduced. Through the post-functionalization of these complexes, it could be possible to rational design and synthesize POV-based hybrid materials with different vanadium oxidation state, which may lead to bright applications in photocatalysis and magnetic materials. Organic functionalization could bring POVs into a new world where there is full of challenges and opportunities.

However, it should be believed that the future of the development of POVs is bright although the navigation road is still far away. Thus, we will make unremitting effortsaimed at the huge treasure at the end of the great route and we trust that the advanced inorganic-organic hybrids based on POVs could make a significant contribution to our world and change our life positively.

\section{References}

1. Gao YZ, Chi YN, Hu CW (2014) 83: 242.

2. Long DL, Tsunashima R, Cronin L (2010) Polyoxometalates: building blocks for functional nanoscale systems. Angew Chem Int Ed 49(10): $1736-1758$

3. Klemperer WG, Marquart TA, Yaghi OM (1992) New Directions in Polyvanadate Chemistry: From Cages and Clusters to Baskets, Belts, Bowls, and Barrels. Angew Chem Int Ed 31(1): 49-51.

4. Chen Q ,Zubieta J (1990) Synthesis and structural characterization of a polyoxovanadate coordination complex with a hexametalate core: [(n-C4H9)4N]2[V6O13\{02NC(CH2O)3\}2]. Inorg Chem 29(8): 14561458.

5. Chen Q, Goshorn DP, Scholes CP, Tan XL, Zubieta J (1992) Coordination compounds of polyoxovanadates with a hexametalate core. Chemical and structural characterization of [VV6013[(OCH2)3CR]2]2[VV6011(OH)2[(OCH2)3CR]2], [VIV4VV209(OH)4[(OCH2)3CR]2]2-, and [VIV6O7(OH)6](OCH2)3CR]2]2-. Am Chem Soc J 114(12): 46674681.

6. Khan MI, Chen Q Höpe H, Parkin S, O'Connor CJ, et al. (1993) Goshorn DP Inorg Chem 32: 2929.

7. Müller A, Meyer J, Bögge H, Stammler A, Botar A, Z. Anorg Allg Chem (1995) 621:1818.

8. Proust A, Matt R Villanneau B, Guillemot G, Gouzerh P, Izzet G, et al (2012) Functionalization and post-functionalization: a step towards polyoxometalate-based materials. Chem Soc Rev 41(22): 7605.

9. Han JW, Hill GL (2007) J. Am Chem Soc 129: 15094.

10. Han JW, Hardcastle KI, Hill CL (2006) Eur J Inorg Chem 13: 2598.

11. Santoni MP, Pal A K, Hanan GS, Tang MC, Venne K, et al. (2012) Chem Commun 48: 200.

12. Santoni MP, Pal AK, Hanan GS, Proust A, Hasenknopf B (2011) Discrete covalent organic-inorganic hybrids: terpyridine functionalized polyoxometalates obtained by a modular strategy and their metal complexation. Eur J Inorg Chem 50(14): 6737-6745.

13. Yin PC, Wu PF, Xiao ZC, Li D, Bitterlich E, et al. (2011) Angew Chem Int Ed 50: 2521.

14. Wu PF, Xiao ZC, Zhang J, Hao J, Chen JK, et al. (2011) Chem Commun 47: 5557. 
15. Li D, Song J, Yin PC, Simotwo S, Bassler AJ, et al. (2011) Inorganicorganic hybrid vesicles with counterion- and $\mathrm{pH}$-controlled fluorescent properties. J Am Chem Soc 133(35): 14010.

16. Bayaguud A, Chen K, Wei YG (2016) Facile synthesis of an organicallyderivatized hexavanadate containing the remote amino group, $\mathrm{TBA}_{2}\left[\mathrm{~V}_{6} \mathrm{O}_{13}\left\{\left(\mathrm{OCH}_{2}\right)_{3} \mathrm{CNH}_{2}\right\}_{2}\right]$. Cryst Eng Comm 18(22): 4042.

17. Bayaguud A, Chen K, Wei YG (2016) Controllable synthesis of polyoxovanadate-based coordination polymer nanosheets with extended exposure of catalytic sites. Nano Res 9(12): 3858.
18. Bayaguud A, Li JD, She S, Wei YG (2017) Dalton Trans 46: 4602.

19. Xiao ZC, Chen K, Wu BL, Li WJ, Wu PF, et al. (2016) Eur J Inorg Chem 6 : 808.

20. Hu XL, Xiao ZC, Huang B, Hu XK, Cheng M, et al. (2017) Dalton Trans 46:8505.

21. Xie YQ, Huang B, Xu C, Hu XL, Chen WZ, et al. (2017) Inorg Chem Comm 84: 96.

\section{CC) This work is licensed under Creative}

To Submit Your Article Click Here: Submit Article

DOI: 10.32474/AOICS.2018.01.000125

\section{AOICS}

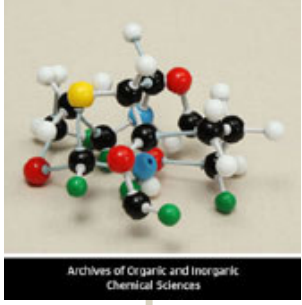

Archives of Organic and Inorganic Chemical Sciences

\section{Assets of Publishing with us}

- Global archiving of articles

- Immediate, unrestricted online access

- Rigorous Peer Review Process

- Authors Retain Copyrights

- Unique DOI for all articles 